\title{
Perioperative anaesthetic concerns during paediatric epilepsy surgeries: A retrospective chart review
}

\author{
Veena Sheshadri, Seetharam Raghavendra ${ }^{1}$, B. A. Chandramouli
}

\begin{abstract}
Background: Epilepsy in children is a common medical condition which usually responds well to antiepileptic drugs (AEDs). Surgical intervention is required in $30-40 \%$ of patients for refractory epilepsy. Paediatric patients present challenges to neurosurgeons as well as anaesthesiologists in view of the inherent physiological and developmental differences. We aimed to analyse the key perioperative factors affecting the paediatric epilepsy surgeries as well as the intraoperative and intensive care unit (ICU) complications and safety of the procedure in children. Materials and Methods: We performed a retrospective chart review of perioperative data of 39 patients who underwent surgery for refractory epilepsy. Results: The surgical procedures were either resective or disconnective. The fraction of blood volume lost intraoperatively correlated well with the duration of surgery $(P<0.001, r=0.76)$. In the postoperative course in ICU, 7 children required postoperative ventilation and I 4 developed fever, which was significantly more $(P<0.00 \mathrm{I})$ after disconnective surgeries. Conclusions: The blood loss and delayed recovery were found to be the main anaesthetic concerns perioperatively, especially with disconnective surgeries. The choice of anaesthetic agents did not affect electrocorticography or the course of surgery. Neurological complications and fever of non-infectious aetiology must be considered in the postoperative period in ICU. Paediatric epilepsy surgery can be safe and feasible with multidisciplinary team approach.
\end{abstract}

Key words: Paediatric anaesthesia, paediatric epilepsy surgery, refractory epilepsy

\section{INTRODUCTION}

Epilepsy is a common medical condition affecting paediatric population with a good response to antiepileptic drugs (AEDs). However, in $30-40 \%$ of children, seizures become medically refractory and can adversely affect the brain development, learning,

Department of Anaesthesia, Toronto Western Hospital, Toronto, Ontario, Canada, Departments of ${ }^{1}$ Neurology and ${ }^{2}$ Neurosurgery, Vikram Hospitals, Bengaluru, Karnataka, India

Address for correspondence:

Dr. Veena Sheshadri, Department of Anaesthesia,

Toronto Western Hospital, McL2-405, 399 Bathurst Street,

Toronto, Ontario, M5T2S8, Canada.

E-mail: drveena_4u@yahoo.co.in

\begin{tabular}{|l|l|}
\hline \multicolumn{2}{|c|}{ Access this article online } \\
\hline Quick Response Code: & Website: \\
\hline & www.jnaccjournal.org \\
\cline { 2 - 2 } & \\
\hline
\end{tabular}

language and the quality of life. ${ }^{[1]}$ These patients may require surgical intervention for refractory epilepsy with benefits in the form of either seizure freedom or reduced seizure frequency. The choice includes resection of the epileptogenic focus or neuronal disconnection. ${ }^{[2-5]}$

In view of the inherent physiological and developmental differences, paediatric patients present challenges to neurosurgeons as well as anaesthesiologists. ${ }^{[6]}$ There are limited literatures on anaesthetic management during epilepsy surgeries in children. ${ }^{[1,6-9]}$ Hence, we retrospectively reviewed paediatric patients who underwent surgery for medically refractory epilepsy. We highlight the perioperative anaesthetic issues and postoperative intensive care concerns during epilepsy surgeries at our centre.

This is an open access article distributed under the terms of the Creative Commons Attribution-NonCommercial-ShareAlike 3.0 License, which allows others to remix, tweak, and build upon the work non-commercially, as long as the author is credited and the new creations are licensed under the identical terms.

For reprints contact: reprints@medknow.com

How to cite this article: Sheshadri $V$, Raghavendra $S$, Chandramouli BA. Perioperative anaesthetic concerns during paediatric epilepsy surgeries: A retrospective chart review. J Neuroanaesthesiol Crit Care 2016;3:110-4. 
The primary objective of the study was to analyse the key perioperative factors such as anaesthetic management, duration of procedure and intensive care concerns during epilepsy surgeries in paediatric population. The secondary objective was to determine intra-operative and post-operative Intensive Care Unit (ICU) complications and safety of the procedure.

\section{MATERIALS AND METHODS}

This study was designed as a retrospective cohort study. Institutional Ethics Committee approval was taken for collection of medical records and analysis of data. All patients under the age of 18 years who underwent epilepsy surgeries for refractory epilepsy between 2011 and 2015 were included. Patients who underwent vagal nerve stimulation for refractory epilepsy were excluded. A total of 39 medical records were reviewed.

Pre-surgical workups relevant to each case were done on outpatient basis and included magnetic resonance imaging brain, video electroencephalography, brain positron emission tomography-computed tomography and neuropsychological assessment, along with basic laboratory investigations.

Patients did not receive any premedication. AEDs were continued on the morning of surgery according to the neurologist's advice. Intraoperatively, patient monitoring included electrocardiogram, blood pressure, pulse oximetry, end tidal gas concentrations, nasopharyngeal temperature and neuromuscular junction monitoring by train-of-four monitoring. All children received arterial cannula for continuous blood pressure monitoring, and children $<15 \mathrm{~kg}$ and those with difficult intravenous (IV) access received central venous cannulae. Most of the children $<6$ years had inhalational induction with sevoflurane and others were given propofol $2-2.5 \mathrm{mg} / \mathrm{kg}$. Analgesia was achieved with fentanyl 2-3 $\mu \mathrm{g} / \mathrm{kg}$ and neuromuscular blockade with atracurium. Maintenance was achieved using oxygen $\left(\mathrm{O}_{2}\right)$ :air:sevoflurane and fentanyl $1 \mu \mathrm{g} / \mathrm{kg}$ boluses. Temperature was maintained between 35 and $37^{\circ} \mathrm{C}$ using forced air warming blankets. During the electrocorticographic (ECoG) monitoring, sevoflurane was maintained at $<0.5$ minimum alveolar concentration (MAC) with $\mathrm{O}_{2}$ :air and those requiring motor cortex stimulation (MCS) did not receive neuromuscular blocking (NMB) drug. Children were considered to have delayed recovery, if the recovery was delayed beyond $30 \mathrm{~min}$. All the patients were directly transferred to post-operative ICU after the surgery. In ICU, post-operative nausea and vomiting was treated with ondansetron $(50 \mu \mathrm{g} / \mathrm{kg})$, analgesia was with fentanyl $0.5-1 \mu \mathrm{g} / \mathrm{kg}$ every hour and paracetamol suppository $(20 \mathrm{mg} / \mathrm{kg})$ or tablets $(10-15 \mathrm{mg} / \mathrm{kg})$ every $6 \mathrm{~h}$.
Data were collected by reviewing the patient medical records. The parameters collected were age, gender, weight, current AEDs, preoperative investigations, duration of anaesthesia and surgery, blood loss, blood transfusion, body temperature, postoperative ventilation, ICU stay and complications.

\section{Statistical analysis}

Descriptive and inferential statistical analysis was carried out in the present study. Results on continuous measurements are presented as mean \pm standard deviation or median with percentile and results on categorical measurements are presented in number (\%). Significance is assessed at 5\% level of significance. Chi-square test was used to find the significance of study parameters on categorical scale between two groups. Relationship between variables was analysed applying Pearson's product moment correlation.

\section{RESULTS}

Thirty-nine children were operated during the study period. The surgical procedures were either resective $(n=20)$ such as excision of focal cortical dysplasia, lesionectomies, lobectomies, amygdalohippocampectomy or disconnective $(n=19)$ such as corpus callosotomy, hemispherectomy, posterior quadrantectomies. Two patients underwent invasive intracranial electrode placement and seizure focus resection. There were varied aetiologies of epilepsy such as focal cortical dysplasia (38.5\%), cortical lesions (28.2\%), Lennox-Gastaut syndrome (18\%), temporal sclerosis, hemimegalencephaly and porencephalic cyst $(15.3 \%)$. The demography and baseline data are shown in Table1. Preoperative haemoglobin was $12.82 \pm 1.76 \mathrm{~g} / \mathrm{dl}$, coagulation parameters and liver function tests were within

\section{Table 1: Demography and baseline data}

\begin{tabular}{lc}
\hline Parameter & Mean \pm SD \\
\hline Age (years) & $10.07 \pm 4.72$ \\
Gender (male:female) & $26: 13$ \\
Body weight (kg) & $34.32 \pm 17.48$ \\
AEDs (n) & $3.20 \pm 0.97$ \\
AEDs (percentage of patients taking each) & \\
Levetiracetam & 66 \\
Clobazam & 54.5 \\
Carbamazepine & 35.9 \\
Sodium valproate & 33 \\
Topiramate & 28 \\
Lamotrigine and oxcarbazepine (each) & 23 \\
Miscellaneous: Zonisamide, clonazepam, & 50 \\
lacosamide, phenobarbitone, eptoin & \\
\hline Data are displayed as mean &
\end{tabular}

Data are displayed as mean \pm SD, AEDs = Antiepileptic drugs, $\mathrm{SD}=$ Standard deviation 
normal limits. None of the patients were on a ketogenic diet at the time of evaluation.

Mean duration of surgery was 4:53 $\pm 1: 21$ (h) and that of anaesthesia was 5:51 \pm 1:20 (h) [Table 2]. The fraction of blood volume lost was significantly more depending on the duration of surgery. There was significant $(P<0.001)$ correlation between these two variables [Figure 1 - Pearson $r=0.76$ ]. The red cell transfusion trigger was $8 \mathrm{~g} / \mathrm{dl}$. About 17 children received packed red cell transfusion and no other blood component transfusion was required. ECoG monitoring was done in all patients and MCS was done in five patients.

In the post-operative course in ICU, seven patients required post-operative ventilation since the recovery was delayed. The diagnosis in these patients was focal cortical dysplasia (4), cortical lesions (2) and Lennox-Gastaut syndrome (1). Five patients developed hemiparesis and two patients had post-operative seizures which were controlled with AEDs. Fourteen children developed fever and it was significantly $(P<0.001)$ more in children who underwent disconnective surgeries [Table 3]. The overall ICU stay was $24.1 \pm 13.42 \mathrm{~h}$ [Table 4]. None of the patients had any complications related to anaesthesia or cortical stimulation. There was no mortality or sudden death during the hospital stay for epilepsy surgery.

\section{DISCUSSION}

The surgical procedures for epilepsy involve either resection of temporal or extra-temporal seizure focus or extensive disconnective technique. There are limited reviews on anaesthetic concerns for paediatric epilepsy surgeries, ${ }^{[1,6-8]}$ and only one study which has retrospectively analysed the complications associated with anaesthetic management during resective seizure

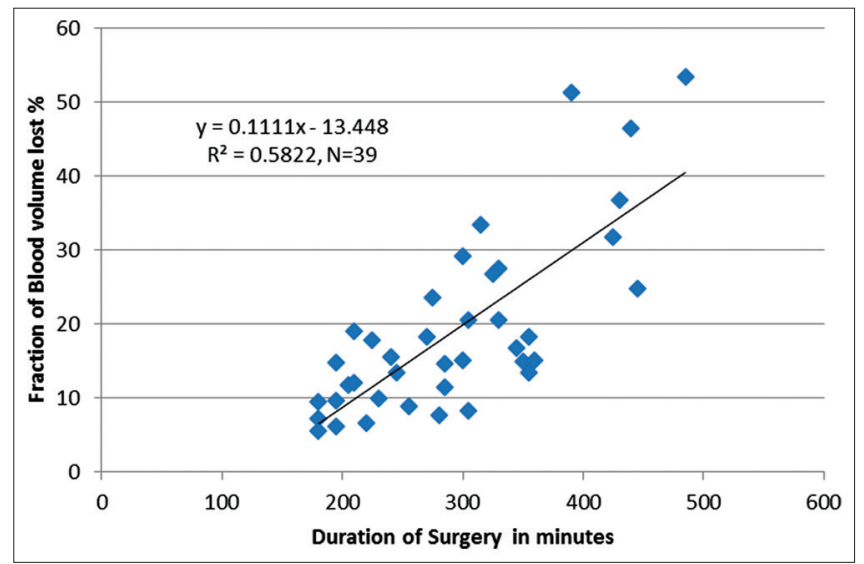

Figure 1: Linear regression analysis. A significant positive correlation (Pearson $r=0.76, P<0.0001$ ) was observed between the intra-operative blood loss (expressed as fraction of the total blood volume) and the duration of surgery surgeries in children. ${ }^{[9]}$ We aimed to highlight the anaesthetic management, ICU concerns, perioperative complications and safety profile of resective and disconnective paediatric epilepsy surgeries at our centre.

Anaesthetic management included induction using IV propofol or inhalational induction with sevoflurane in young children. Sevoflurane is suitable for children because of non-irritant effect on upper airways and short induction and recovery times, though it is known to have epileptogenic potential. ${ }^{[10-12]}$ Maintenance anaesthetic was with $\mathrm{O}_{2}$ :air:sevoflurane (0.5-1 MAC) with $1 \mu \mathrm{g} / \mathrm{kg}$ fentanyl boluses. ECoG, which is the recording of cortical potentials, was done using either strip or grid electrodes placed on the cortical surface. It was recorded pre- and post-resection of the epileptogenic focus to detect interictal discharges and to evaluate the extent of surgery. MAC was maintained at $<0.5$ during ECoG, and fentanyl $1 \mu \mathrm{g} / \mathrm{kg}$ was used to attenuate any reflex responses. This technique did not lead to any interference

\section{Table 2: Intra-operative and admission data}

\begin{tabular}{lc}
\hline Parameter & Mean \pm SD \\
\hline Duration of surgery (hh) & $4: 53 \pm 1: 21$ \\
Duration of anaesthesia (hh) & $5: 51 \pm 1: 23$ \\
Post-operative ventilation (min) & $51.42 \pm 20.55$ \\
ICU stay (hh) & $24: 06 \pm 13: 25$
\end{tabular}

Data are displayed as mean \pm SD. $\mathrm{hh}=$ Hours, ICU = Intensive Care Unit, SD = Standard deviation

Table 3: Fever incidence according to the type of surgery

\begin{tabular}{lccc}
\hline Fever & \multicolumn{2}{c}{ Type of surgery } & $\begin{array}{c}\text { Total } \\
(\boldsymbol{n}=\mathbf{3 9 )}\end{array}$ \\
\cline { 2 - 3 } & $\begin{array}{c}\text { Resective } \\
(\boldsymbol{n}=\mathbf{2 0}) \boldsymbol{\%}\end{array}$ & $\begin{array}{c}\text { Disconnective } \\
(\boldsymbol{n}=\mathbf{1 9 )} \%\end{array}$ & \\
\hline No & $19(95)$ & $6(31.6)$ & $25(63.2)$ \\
Yes (days) & $1(5.0)$ & $13(68.4)$ & $14(36.8)^{*}$ \\
$1-2$ & $1(5.0)$ & $7(36.8)$ & $8(21.1)^{*}$ \\
$3-4$ & $0(0)$ & $4(21.1)$ & $4(10.5)^{*}$ \\
$>4$ & $0(0)$ & $2(10.5)$ & $2(15.3)$ \\
\hline${ }^{*} P<0.05$ using Chi-square test, Incidence of fever was \\
significant with disconnective surgeries and in the first \\
4 days post-operatively
\end{tabular}

Table 4: Intensive Care Unit data

\begin{tabular}{lc}
\hline ICU data & $\boldsymbol{n}$ (resective:disconnective) \\
\hline Post-operative ventilation & $7(2: 5)$ \\
Fever & $14(1: 13)$ \\
Hemiparesis & $5(3: 2)$ \\
Seizures & $2(1: 1)$ \\
\hline
\end{tabular}

ICU = Intensive Care Unit 
with ECoG monitoring. In surgeries requiring resection near motor area, cortical stimulation of the motor strip was done with bipolar stimulator and the response was seen by direct visualisation of contralateral limb muscle movement or electromyography. In such surgeries, morphine $0.05 \mathrm{mg} / \mathrm{kg}$ IV was given and NMBs were avoided during that phase. The choice of anaesthetic agents for maintenance of anaesthesia is not associated with varied outcome when properly titrated. ${ }^{[13]}$

There were no significant intraoperative haemodynamic fluctuations. Central venous catheter placement is controversial as the pressures may not accurately reflect intravascular volume. ${ }^{[14]}$ In our patients, only young children $<15 \mathrm{Kg}$ received both arterial and central venous catheter considering larger body surface area and lesser allowable blood loss and other children received only arterial cannula.

The potential for blood loss is high during craniotomies in children. Depending on the maximum allowable blood loss, visual assessment and haemodynamics and the intra-operative haemoglobin values, the blood transfusion has to be initiated. Haemorrhagic derangements represent the leading cause of mortality in very young patients after intra-operative blood loss. ${ }^{[7]}$ We found that blood loss requiring transfusion were significantly higher in the children who underwent disconnective surgeries when compared to resective surgeries though these were unmatched groups (Fraction of blood volume lost $14.23 \%$ vs. $24.35 \%$ in resective vs. disconnective, respectively, $P=0.0081$ ). Literature review suggests similar association between disconnective surgeries and significant blood loss. ${ }^{[15-19]}$ Resective surgeries are also associated with considerable blood loss as shown by Thudium et al..$^{[9]}$ Previous studies have demonstrated association between AEDs and coagulation derangements, ${ }^{[20-22]}$ but we did not find any preoperative coagulation abnormalities or increase in intra-operative blood transfusions with number of AEDs, similar to reports by Manohar et al. ${ }^{[23]}$ The relative blood loss (fraction of total blood volume) significantly correlated with duration of surgery [Figure 1], similar to the observations of Thudium et al. $(P=0.0003, r=0.52) .{ }^{[9]}$ Temperature was maintained between $35-37^{\circ} \mathrm{C}$. Majority had mild hypothermia, but there was no moderate or severe intra- or post-operative hypothermia in any of the children.

Serial neurological examinations, haemodynamic management, maintenance of airway and oxygen saturation, treatment of seizures, nausea, vomiting and postoperative pain are important concerns in ICU.

Delayed recovery and postoperative ventilation after anaesthesia were seen in seven patients. Those who had delayed recovery were shifted to ICU for ventilation and were extubated when they were eligible. The reasons for delayed recovery could have been due to long duration of anaesthesia, pre-existing neurological condition, AED's or nature of surgical procedure itself. Delayed recovery was seen more often in our patients after prolonged resections and disconnections such as corpus callosotomy or hemispherectomies. The latter two procedures are often associated with increased post-operative somnolence, in turn necessitating mechanical ventilation until the patient becomes more alert. ${ }^{[6]}$

Postoperatively, 14 patients were febrile after disconnective surgeries and only one after resective surgeries. The temperature was $38.5^{\circ} \mathrm{C}$ or above and mostly started on the second post-operative day and lasted for 2-3 days except in one patient where it lasted for 7 days. Fever after paediatric epilepsy surgeries, especially hemispherectomies, has been acknowledged for many years. ${ }^{[24]}$ Fever with infection is common after larger resections as in multilobar resections, hemispherectomies and with ventriculostomy catheters. As observed by Phung et al., fever and elevated leucocyte count were common after paediatric epilepsy surgery, but cerebrospinal fluid infections were uncommon. ${ }^{[25]}$ In our patients, the markers of infection such as elevated leucocyte count or positive cultures were ruled out thus suggesting non-infectious aetiology of fever. The surgical technique, causative pathology, ${ }^{[26]}$ blood in the ventricles ${ }^{[27,28]}$ and surgical damage to the parenchyma and the associated local inflammatory response ${ }^{[24]}$ have all been postulated for the non-infectious aetiology of post-operative fever following epilepsy surgery, especially after neuronal disconnection. Supportive therapy remains the mainstay of managing these febrile illnesses of non-infectious aetiology in the post-operative period.

Limitations of this study are its retrospective nature, small number of patients affecting the power of the study, unmatched cohorts precluding comparative statistics; but prevalence of children with similar demographics undergoing either resective or disconnective surgeries is less.

\section{CONCLUSION}

In summary, perioperative factors that are a cause for concern in anaesthetic management for paediatric epilepsy surgeries include intra-operative blood loss and delayed recovery, especially in disconnective surgeries. The delay in recovery may necessitate ventilatory support in the ICU postoperatively. Duration of surgery proportionately affected the fraction of total blood volume lost with good correlation. Appropriate titration of maintenance of anaesthetic agents ensured no 
interference with ECoG. The neurological complications in the ICU as well as the fever of non-infective aetiology must be considered in post-operative care. Multidisciplinary team approach and management can render epilepsy surgery in children safe and feasible.

\section{Financial support and sponsorship}

Nil.

\section{Conflicts of interest}

There are no conflicts of interest.

\section{REFERENCES}

1. Koh JL, Egan B, McGraw T. Pediatric epilepsy surgery: Anesthetic considerations. Anesthesiol Clin 2012;30:191-206.

2. Schramm J, Clusmann H.The surgery of epilepsy. Neurosurgery 2008;62 Suppl 2:463-81.

3. Dorfmüller G, Delalande O. Pediatric epilepsy surgery. Handb Clin Neurol 2013;111:785-95.

4. Kunieda T, Kikuchi T, Miyamoto S. Epilepsy surgery: Surgical aspects. Curr Opin Anaesthesiol 2012;25:533-9.

5. Harvey AS, Cross JH, Shinnar S, Mathern GW; ILAE Pediatric Epilepsy Surgery Survey Taskforce. Defining the spectrum of international practice in pediatric epilepsy surgery patients. Epilepsia 2008;49:146-55.

6. Soriano SG, Bozza P. Anesthesia for epilepsy surgery in children. Childs Nerv Syst 2006;22:834-43.

7. Pietrini D, Zanghi F, Pusateri A, Tosi F, Pulitanò S, Piastra M. Anesthesiological and intensive care considerations in children undergoing extensive cerebral excision procedure for congenital epileptogenic lesions. Childs Nerv Syst 2006;22:844-51.

8. Soriano SG, Eldredge EA, Rockoff MA. Pediatric neuroanesthesia. Neuroimaging Clin N Am 2007;17:259-67.

9. Thudium MO, von Lehe M, Wessling C, Schoene-Bake JC, Soehle M. Safety, feasibility and complications during resective pediatric epilepsy surgery: A retrospective analysis. BMC Anesthesiol 2014;14:71.

10. Constant I, Dubois MC, Piat V, Moutard ML, McCue M, Murat I. Changes in electroencephalogram and autonomic cardiovascular activity during induction of anesthesia with sevoflurane compared with halothane in children. Anesthesiology 1999;91:1604-15.

11. Constant I, Seeman R, Murat I. Sevoflurane and epileptiform EEG changes. Paediatr Anaesth 2005;15:266-74.

12. Vakkuri A,Yli-Hankala A, SärkeläM,Lindgren L, Mennander S, Korttila $\mathrm{K}$, et al. Sevoflurane mask induction of anaesthesia is associated with epileptiform EEG in children. Acta Anaesthesiol Scand 2001;45:805-11.

13. Todd MM, Warner DS, Sokoll MD, Maktabi MA, Hindman BJ,
Scamman FL, et al. A prospective, comparative trial of three anesthetics for elective supratentorial craniotomy. Propofol/ fentanyl, isoflurane/nitrous oxide, and fentanyl/nitrous oxide. Anesthesiology 1993;78:1005-20.

14. Soriano SG, Eldredge EA, Rockoff MA. Pediatric neuroanesthesia. Anesthesiol Clin North America 2002;20:389-404.

15. Carson BS,Javedan SP,Freeman JM,Vining EP,Zuckerberg AL, Lauer JA, et al. Hemispherectomy: A hemidecortication approach and review of 52 cases.J Neurosurg 1996;84:903-11.

16. Griffiths PD, Welch RJ, Gardner-Medwin D, Gholkar A, McAllister V.The radiological features of hemimegalencephaly including three cases associated with proteus syndrome. Neuropediatrics 1994;25:140-4.

17. Peacock WJ, Wehby-Grant MC, Shields WD, Shewmon DA, Chugani HT, Sankar R, et al. Hemispherectomy for intractable seizures in children: A report of 58 cases. Childs Nerv Syst 1996;12:376-84.

18. Taha JM, Crone KR, Berger TS. The role of hemispherectomy in the treatment of holohemispheric hemimegaloencephaly. J Neurosurg 1994;81:37-42.

19. Vining EP, Freeman JM, Pillas DJ, Uematsu S, Carson BS, Brandt J, et al. Why would you remove half a brain? The outcome of 58 children after hemispherectomy-the Johns Hopkins experience: 1968 to 1996. Pediatrics 1997;100 (2 Pt 1):163-71.

20. Finsterer J,Pelzl G, Hess B.Severe, isolated thrombocytopenia under polytherapy with carbamazepine and valproate. Psychiatry Clin Neurosci 2001;55:423-6.

21. Holtzer CD, Reisner-Keller LA. Phenytoin-induced thrombocytopenia. Ann Pharmacother 1997;31:435-7.

22. Gerstner T, Teich M, Bell N, Longin E, Dempfle CE, Brand J, et al. Valproate-associated coagulopathies are frequent and variable in children. Epilepsia 2006;47:1136-43.

23. Manohar C,Avitsian R, Lozano S, Gonzalez-Martinez J,Cata JP. The effect of antiepileptic drugs on coagulation and bleeding in the perioperative period of epilepsy surgery: The Cleveland clinic experience. J Clin Neurosci 2011;18:1180-4.

24. de Almeida AN, Marino R Jr., Aguiar PH, Teixeira MJ. Postoperative fever after hemispherectomy: The role of non-infectious factors. Seizure 2006;15:340-3.

25. Phung J, Mathern GW, Krogstad P. Timing and predictors of fever and infection after craniotomy for epilepsy in children. Pediatr Infect Dis J 2013;32:450-9.

26. de Almeida AN, Marino RJr., Marie SK, Aguiar PH, Teixeira MJ. Factors of morbidity in hemispherectomies: Surgical technique x pathology. Brain Dev 2006;28:215-22.

27. Garibaldi RA, Brodine S, Matsumiya S, Coleman M. Evidence for the non-infectious etiology of early postoperative fever. Infect Control 1985;6:273-7.

28. Schwarz S, Häfner K, Aschoff A, Schwab S. Incidence and prognostic significance of fever following intracerebral hemorrhage. Neurology 2000;54:354-61. 